\title{
SONHOS DE MULHERES ESCRITORAS DA PERIFERIA
}

\section{DREAMS OF PERIPHERAL WRITING WOMEN}

Melissa Rosa Teixeira Mendes*

Igor Gastal Grill**

MICELI, Sergio. Sonhos da periferia: inteligência argentina e mecenato privado. São Paulo: Todavia, 2018. $184 \mathrm{p}$.

A proposta desta resenha é enfatizar uma das dimensões do livro Sonhos da periferia: inteligência argentina e mecenato privado, de Sergio Miceli, frequentemente presente nas suas reflexões, porém pouco realçada nas apreciações sobre os empreendimentos do autor, qual seja, o destaque dado ao lugar das mulheres nos processos e fenômenos investigados. Assim, devemos admitir que tomamos essa publicação recente mais como pretexto para pensar em um significativo index de questões que foram tratadas nos artigos deste dossiê.

São muitas as chaves interpretativas passíveis de serem mobilizadas para situar as "obras" ou perscrutar os investimentos e rendimentos analíticos das tantas pesquisas realizadas pelo sociólogo e professor titular da Universidade de São Paulo (USP). No extenso rol de trabalhos publicados, destacam-se aqueles que focalizam microcosmos do campo cultural no Brasil, aos quais Mi-

\footnotetext{
* Doutoranda junto ao Programa de Pós-graduação em Ciências Sociais da Universidade Federal do Maranhão - UFMA - (São Luís/MA/BR). Integrante do LEEPOC/UFMA (Laboratório de Estudos de Elites Políticas e Culturais). E-mail: melissa.rosa.tm@gmail.com

** Professor e pesquisador do Programa de Pós-Graduação em Ciências Sociais e do Departamento de Sociologia e Antropologia da Universidade Federal do Maranhão - UFMA - (São Luís/MA/BR). Bolsista de produtividade em pesquisa do CNPq. Coordenador do LEEPOC/UFMA (Laboratório de Estudos de Elites Políticas e Culturais). E-mail: igorgrill@terra.com.br
} 
celi dedicou grande parte dos seus esforços na carreira de pesquisador. No entanto, o alcance da sociologia por ele praticada se expande por conta do escopo dos universos empíricos enfrentados, das apostas comparativas entre intelectuais brasileiros e argentinos, notadamente nas últimas décadas, e, igualmente, dos/as seguidores/ as interpelados/as por seus textos. 0 que, junto com o reconhecimento conquistado como um dos principais apropriadores da sociologia bourdieusiana, colabora à sua inscrição na genealogia de pesquisadores responsáveis pela edificação das ciências sociais brasileiras.

Para o que nos interessa aqui, apontamos dois ângulos da abordagem adotada em Sonhos... que são particularmente afeitos ao diálogo com as demais contribuições que compõem a presente coletânea. 0 primeiro é o mais enfaticamente sublinhado por resenhadores: a atenção dada às formas de heteronomia e de dependência cultural que pesam, como injunções, sobre o trabalho intelectual em contextos periféricos, como aqueles vigentes em nações latino-americanas. 0 que permite, como desdobramento, identificar elementos relacionados às imbricações entre atividades culturais e "lutas políticas", condicionadores da produção de bens simbólicos e das representações sobre o mundo social, especialmente no que tange à construção da identidade nacional ${ }^{1}$.
O segundo ângulo de abordagem, muito menos sobrelevada entre seus glosadores, é a especial ênfase conferida aos princípios e lógicas das relações (de poder) entre homens e mulheres nos domínios sociologicamente objetivados pelo autor. Por isso, o "protagonismo de gênero", identificado como traço que particulariza o domínio da literatura na Argentina, é foco de atenção privilegiado nesta resenha. 0 que pode aguçar o desenvolvimento de outras investigações - na linha daquelas feitas por Pontes e Succi² no âmbito de uma sociologia dos intelectuais, com enfoque no "gênero" e considerando os alertas expostos por Reis e Barreira na apresentação deste dossiê -, heuristicamente fortalecidas pelo viés comparatista, no caso em pauta, entre a situação das mulheres escritoras argentinas e as brasileiras.

Sonhos da periferia: inteligência argentina e mecenato privado não é a primeira pesquisa de Sergio Miceli sobre a intelectualidade argentina. Neste livro, o autor retoma cotejamentos entre a vida intelectual argentina e a brasileira, tema de livro de 2012 Vanguardas em retrocesso: ensaios de história social e intelectual do modernismo latino-americano e de outra publicação, organizada em conjunto com a pesquisadora Heloisa Pontes em 2014, Cultura e sociedade: Brasil e Argentina ${ }^{3}$.

0 exercício comparativo não visa apenas potencializar o desenho do per-

\footnotetext{
1. Esse veio de investigação foi perseguido por outros cientistas sociais, além de Miceli, tais como Pécaut (1990), Garcia Jr. (1993), Coradini (2003; 2012), Pontes (1998; 2010) e Reis (2013), para a análise do caso brasileiro; e Sigal (1996; 2012), Neiburg (1997) e Quattrocchi-Woisson (1992; 1997), para o exame do contexto argentino.

2. Consultar as contribuições dessas autoras ao dossiê.

3. Ver menção à coletânea em entrevista de Heloisa Pontes, concedida a Camila Rosatti e Eliana Tavares dos Reis e publicada nesta edição da REPOCS.
} 
fil da inteligência argentina nas décadas de 1920-1930, como também tonificar seus argumentos já bastante difundidos acerca das relações entre os intelectuais e o Estado no Brasil, no mesmo período. Para tanto, Miceli assume como mote as "modalidades antípodas de heteronomia" (p. 10) que, do lado argentino, se expressam na produção cultural subsidiada por patronos da elite (o mecenato privado grifado no subtítulo do livro) e, do lado brasileiro, nas estratégias de cooptação e de intervenção estatal (ou a relação dos escritores com a classe dirigente) ${ }^{4}$.

Além disso, o confronto entre os dois contextos nacionais fez emergir, com pujança, as feições distintivas da experiência portenha. Entre elas, a projeção dos seus protagonistas escritores no plano supranacional e, consequentemente, a "autoimagem triunfante da elite nativa”, que sonhava "erigir, do recesso da periferia, a expressão convincente de uma arte própria, de lavra autóctone, autêntica, liberada de peias nacionais, capaz de se equiparar à melhor literatura do mundo" (p.11).

No primeiro capitulo, "A vanguarda argentina na década de 1920”, o autor delineia a gênese do campo literário argentino por meio de um esboço do contexto histórico ${ }^{5}$, relembrando as heranças colonialistas com a Espanha, e debruçando-se sobre as relações íntimas entre o modernismo argentino e o espanhol - chamando atenção para o caso brasileiro, que, ao contrário, não mantinha as mesmas ligações com o português.

A soma de aportes financeiros robustos (resultantes de investimentos de famílias e figurões do patriciado, bem como de magnatas da imprensa) com a autoestima inflada (ou inflacionada) de escritores portadores de ambiciosas metas de reconhecimento a ser conquistado na seara especificamente literária, não salvaguardaram os produtores culturais dos constrangimentos ditados pela conjuntura política (internacional e doméstica) em ebulição. Miceli demonstra isso esquadrinhando, ao longo dos capítulos, os arranjos específicos àquele caso nacional e ao contexto em tela, que ligam os agentes (suas propriedades sociais) às temáticas e orientações político-doutrinárias.

Ainda no primeiro capítulo, o autor demonstra o quanto as origens sociais dessa geração de intelectuais argentinos constituem um divisor de águas na montagem do campo literário. Os escritores de classes sociais menos abastadas, geralmente imigrantes, escreviam para um público popular. A elite criolla, por sua vez, cooptada pela figura emblemática de Victória Ocampo sob o título da revista literária SUR, escrevia para um público refinado, dominando o campo literário argentino e oficializando o que era ou não arte pura, a “arte pela arte”.

Ocampo é a figura feminina que ganha evidência no segundo capítulo, "A inteligência estrangeirada de SUR”, graças à sua posição à frente da revista literária $S U R$, lançada em 1931, voltada à promoção do sonho de divulgar a cultura da elite criolla argentina. Idealizadora e mecenas da $S U R$, escritora, intelectual, personalidade pertencente à elite argentina e frequentadora das altas rodas da sociedade, Victória Ocampo edificou a revista capitaneando e

4. Tema de seu livro mais conhecido e debatido (MICELI, 1979).

5. Para os leitores interessados na sócio-história da literatura argentina e sua contribuição à construção da identidade nacional, apreendida em um lapso de tempo mais longo, sugerimos a leitura dos trabalhos de Quattrocchi-Woisson (1992; 1997). 
abrigando, sob seu prestígio, a nata dos intelectuais vanguardistas argentinos. Sob sua tutela, esse grupo de intelectuais ambicionava ser reconhecido internacionalmente, não somente em virtude de seu conhecimento no plano cultural, mas da ligação com a língua espanhola, e também pelos vínculos da inteligência argentina com as de outros países ${ }^{6}$.

Sob o patrocínio de figuras cosmopolitas, familiarizadas com o melhor do mundo letrado e das artes e membros ilustres da elite dirigente, SUR se constituiu em veículo de autoridade no tocante à organização da vida cultural. Seus membros, segundo demonstrado por Miceli através da composição das trajetórias, se conheciam e frequentavam os mesmos redutos de sociabilidade, clubes, embaixadas, cruzeiros; faziam viagens frequentes à Europa onde residiam por temporadas; realizavam parte dos estudos em colégios no exterior.

Traçando a trajetória da revista, o autor analisa a economia e a sociedade formada ao seu redor, ilustrando como a SUR exercia uma função de "banco central da cultura grã-fina”, ou seja, por meio de um mecenato privado, dispensava incentivos e legitimidade aos escritores próximos ao corpo restrito de editores: manejava as redes de aliança e proteção mútua pelo intercâmbio de resenhas e pleitos de reverência; regulava cotações no mercado de credenciais e de notoriedades; condenava ao descrédito e à relegação as obras e a reputação de escritores concorrentes que haviam conquistado espaço na mídia impressa e assentimento do público-alvo da indústria cultural.

Acentuamos que Miceli não se deteve somente nas trajetórias dos editores da revista e de seus escritos, mas sobre a revista como um todo. Procurando abarcar publicidades, fotografias, maquetes de arquitetura, anúncios de antiquários, de livrarias de arte e de obras raras, e toda sorte de bens compatíveis com o "gosto" de um público restrito, um minoria endinheira e/ou culta.

A liderança e protagonismo de Victoria Ocampo definiram os posicionamentos da SUR que, durante muitos anos, mesmo diante de inúmeros conflitos políticos internos e externos, reivindicou uma postura "neutra" ou uma "postura olímpica de abstenção” (p. 40). Contudo, a partir da Segunda Guerra Mundial, essa atitude da revista sofre mudanças, com Ocampo declarando seu apoio aos aliados e os posicionamentos da SUR sendo direcionados a exigências de defınição do "lado" do governo no conflito. Sob o registro ensaístico, gerenciado por viajantes e nativos, teriam constituído uma forma de fazer política "por procuração" ou “à distância”, e do mesmo modo passaram a discutir a questão nacional no lastro de uma ideia de civilização ${ }^{7}$.

Miceli trata do fazer literário na SUR explorando a estética de Jorge Luís Borges, com ênfase nos seus escritos de tom criollis-

6. Outro retrato dessa personagem pode ser encontrado em Neiburg (1997). Situando-a nos debates em torno do peronismo no período subsequente ao tratado por Miceli, o antropólogo destaca, como principal argumento de autoridade de Ocampo para se posicionar sobre o tema, a visão testemunhal que oferece. Seu gênero predileto, a autobiografia, revelaria a consagração do seu caso como "mulher de elite" que teria subvertido seu destino, ao mesmo tempo em que informa a base primordial (quase exclusiva) de sua legitimidade nos embates políticos, a experiência pessoal.

7. Nesse ponto, algumas aproximações com outros estudos sobre as formas de intervenção dos profissionais da manipulação dos bens simbólicos na política argentina podem ser pertinentes. Sigal (1996) ponderou que o papel de mediação dos intelectuais nesse país é pautado por duas referências exógenas, que dissolvem a 
ta e nos ensaios sobre o caráter nacional. 0 programa estético da revista, que pretendia a uma arte argentina entendida como uma arte da elite criolla, encontrou seu melhor representante em Borges, pertencente ao mesmo universo social de Victoria Ocampo. Borges estava à altura de realizar o sonho da $S U R$, pois "incensava o ego do leitor ao lhe conferir o privilégio de sentir-se dotado do cabedal indispensável ao desfrute de iguarias; ato contínuo, ele nivelou o status do leitor ao do escritor, como que turvando a agência autoral" (p. 92).

0 recurso a um conjunto de variáveis estruturais que permitiram, em linhas bem gerais, a caracterização da morfologia daquele espaço nacional e do campo literário em pauta, foi imprescindível para iluminar os efeitos da presença de imigrantes no campo cultural e a centralidade de perfis e papéis de determinadas mulheres na literatura argentina. 0 lugar das escritoras é pontuado como fator distintivo das vanguardas argentinas em relação às brasileiras, verificando entre as primeiras a confıguração de espaços de sociabilidades e institucionais propícios ao protagonismo feminino. E, como pano de fundo, Miceli desvela um mundo em (re)configuração, com a entrada de novos segmentos e categorias, ao mesmo tempo em que calibra os instrumentos de compreensão das clivagens entre produtores, das variações de temáticas e gêneros em concorrência, e das clientelas privilegiadas por cada perfil de especialista da cultura. E vemos que transformações históricas e conjunturais, com uma série de remodelagens de recursos e redefınições nas formas de apreciação cultural, acabaram contribuindo na ampliação do mercado de bens culturais e na possibilidade de profissionalização de escritores que, ao contrário dos notáveis até então dominantes, poderiam viver da sua criação.

Tais elementos ficam arredondados no último ensaio do Sonhos... dedicado à análise das trajetórias de escritores outsiders em relação à distribuição das posições intelectuais dominantes à época. Alfonsina Storni e Horacio Quiroga já publicavam desde 1920 em impressos, e, conforme mencionamos anteriormente, a SUR é de 1931. Portanto, linearmente, poderia haver uma inversão na localização dos ensaios no livro. Entretanto, o fato de estarem fora do contínuo cronológico auxilia no entendimento de aspectos peculiares, sobretudo concernentes às disputas de fronteiras do campo intelectual argentino. Em Voz, sexo e abismo podemos atentar ao contraste da dupla em relação ao círculo elitista da SUR e às dimensões mais disposicionalistas e subjetivistas que o autor lança mão, mormente, à apreensão dos dribles entre oportunidades e obstáculos encarados por Alfonsina Storni.

Distantes das regras de legitimidade do cânone ditado pela inteligência da SUR, Storni e Quiroga direcionaram sua produção à indústria cultural nascente. Com percursos biográficos às margens do círculo de intelectuais consagrados, eles investiram em criações heterodoxas e mais palatáveis a um público diversificado. Tornaram-se

autonomia do campo cultural autóctone: a razão universalista (buscada no 0cidente) e a interpretação sobre os caminhos para a modernidade da nação (que os aproximam das lutas políticas). Desse modo, (re)inventar a cultura nacional, o sentimento de nacionalidade e de argentinidade foi encargo de várias gerações de escritores (principalmente literatos e historiadores), desde o século XIX até os intérpretes do peronismo, como mostraram, além de Sigal (1996), Quattrocchi-Woisson (1997;1992) e Neiburg (1997). 
autores bem-sucedidos em termos de vendas, de repercussão na mídia e junto aos leitores. 0 que contribuiu à conversão das suas vidas em objetos de interesse por parte das revistas de variedades. Ambos se disponibilizaram a participar de entrevistas, matérias especiais e tratamento iconográfico, como possibilidades de consagração distantes daquelas da elite intelectual estabelecida.

Horacio Quiroga parece funcionar como caso de controle da trajetória de Alfonsina Storni e a parceria entre eles ${ }^{8}$, os momentos de encontros e desencontros são reveladores de constrições de gênero, divisões de papéis, usos possíveis de certos recursos, de estratégias eficientes ou precárias de sobrevivência e de produção. Storni foi poetisa e cronista privilegiando assuntos feministas; Quiroga foi contista e novelista de temas sórdidos e escabrosos. Mesmo de início considerados como destoantes no mundo da alta cultura, ele se mantiveram por meio da cobrança de direitos autorais das obras e da colaboração em impressos diversificados (periódicos literários, revistas de variedades, magazines voltados às mulheres, suplementos e colunas em jornais). E, por esse intermédio, ofereceram a um público, principalmente de perfis homólogos, produtos distintos daqueles ao qual se destinava a $S U R$, e consoantes às bases da diversificação do mercado de consumo cultural.

Storni tornou-se colunista assídua de $L a$ Nota (1919) e La Nación (1920), abordando temas da agenda feminista da época, discutindo os impasses enfrentados pelas re- lações de gênero, no âmbito doméstico, no mundo do trabalho, na vida amorosa e no espaço político. Baseava sua escrita em materiais autobiográficos e tecia provocações aos estereótipos do ideal feminino. Como cronista, escreveu sobre assuntos diversos: casamento, adultério, divórcio, salientando como homens e mulheres figuram nesses papéis. E, a partir de sua experiência pessoal, tratou de temáticas consideradas reais ao papel da mulher na sociedade.

Se os textos de Alfonsina Storni fizeram tanto sucesso entre as leitoras de revistas de variedades, é possível que, de algum modo, elas se identificassem com essa escrita. Segundo Miceli, ao rastrear os tópicos abordados pela escritora fica patente a preocupação em abordar problemas sociais que seriam próprios aos das mulheres argentinas: novas relações de gênero e transformações da condição feminina, crise da família, referências aos empecilhos à reprodução tradicional de papéis na divisão social do trabalho.

As discussões do autor, então, estimulam a reflexão, por um lado, sobre os amálgamas entre pulsões derivadas de inscrições sociais, políticas e culturais, bem como autocontroles/censuras decorrentes do pertencimento étnico, de classe, de gênero, etc., franqueando ou obstaculizando o acesso a domínios especializados de intervenção. E, por outro lado, sobre as recomposições na estrutura social que permitem o protagonismo de novos perfis sociais (com experiências, atributos e trunfos díspares), suas adaptações às injunções de cada microcosmo, e os usos/disputas (conscientes ou não)

8. É impossível não associar a forma como Miceli examina a importância dessa parceria amorosa nas trajetórias em questão, à maneira como Pontes (1998) e Succi (neste dossiê) efetuaram, respectivamente, nas análises dos casais Gilda de Mello e Souza e Antonio Candido e Griselda Gambarro e Juan Carlos Distéfano. Ver também Pontes (2010) e a sua entrevista publicada neste dossiê. 
relativos às práticas, gostos e etiquetas (no duplo sentido) legitimadas em lutas sociais. As condições das notabilidades de Victoria Ocampo, fundadora da SUR - revista que permitiu ao campo intelectual argentino se consolidar nas primeiras décadas do século XX -, e de Alfonsina Storni, que mesmo com uma trajetória oposta à de Victoria conseguiu se tornar uma escritora reconhecida pelo grande público (embora não pela intelectualidade estabelecida do período), instigam ao aprofundamento de estudos atentos às trajetórias de mulheres que participam ou são representativas do trabalho de produção, reprodução ou requalificação de bens culturais.

\section{Referências}

CORADINI, O. L. As missões da cultura e da política: confrontos e reconversões de elites culturais e políticas no Rio Grande do Sul (1920-1960).

Estudos Históricos, n. 32, p. 125-144, 2003. . Os usos das ciências humanas e sociais pelo catolicismo e pelo luteranismo e as relações centro/periferia. REPOCS - Revista Pós Ciências Sociais, v. 9, p. 67-99, 2012.

GARCIA JÚNIOR, A. Les Intellectuels et la Conscience Nationale au Brésil. Actes de la Recherche en Sciences Sociales, n. 98, p. 20-33, 1993.

MICELI, S. Intelectuais e classe dirigente no Brasil. Rio de Janeiro: Difel, 1979.

Vanguardas em retrocesso: ensaios de história social e intelectual do modernismo latino-americano. São Paulo: Companhia das Letras, 2012.

MICELI, S; PONTES, H. (Orgs.). Cultura e Sociedade: Brasil e Argentina. São Paulo: Edusp, 2014. NEIBURG, F. Os intelectuais e a invenção do Peronismo. São Paulo: Edusp, 1998.
PÉCAUT, D. Os intelectuais e a política no Brasil: entre o povo e a nação. São Paulo: Ática, 1990.

PONTES, H. Destinos mistos: os críticos do grupo clima em São Paulo (1940-1968). São Paulo: Companhia das Letras, 1998.

Intérpretes da metrópole: história social e relações de gênero no teatro e no campo intelectual, 1940-1968. 1a. ed. São Paulo: Edusp/Fapesp, 2010.

QUATTROCCHI-WOISSON, D. Un Nationalisme de Déracinés. Paris: Editions du Centre National de la Recherche Scientifique, 1992.

. Le rôle de l'histoire et de la littérature dans la construction des mythes fondateurs de la nationalité argentine. In: BOUCHARD, G.; LAMONDE, Y. (Orgs.). La Nation dans tous ses États. Paris: Harmattan, 1997, p. 55-74.

REIS, E. T. Saberes em movimento: transações entre "intelectuais", definições de ciências sociais e a "política”. In: SEIDL, E.; GRILL, I. G. (Orgs.). As ciências sociais e os espaços da política no Brasil. São Paulo: FGV, 2013, p. 21-74.

SIGAL, S. La dérive des intelectuels en Argentine. Paris: Harmattan, 1996. Intelectuais, cultura e política na Argentina. REPOCS - Revista Pós Ciências Sociais, v. 9, p. 51-66, 2012.

Recebido em:10/06/2020

Aprovado em: 29/06/2020 
